\title{
Sampling Method Code
}

National Cancer Institute

\section{Source}

National Cancer Institute. Sampling Method Code. NCI Thesaurus. Code C93668.

A coded value specifying the process used to define a representative set of a population

for a study or statistical activity. 